\title{
Personalised medicine for nonsmall cell lung cancer
}

\author{
Céline Mascaux ${ }^{1,2}$, Pascale Tomasini ${ }^{1,2}$, Laurent Greillier ${ }^{1,2}$ and \\ Fabrice Barlesi ${ }^{1,2}$
}

\author{
Number 3 in the Series "Personalised medicine in respiratory diseases" \\ Edited by Renaud Louis and Nicolas Roche
}

Affiliations: ${ }^{1}$ Aix Marseille University, Assistance Publique Hôpitaux de Marseille, Multidisciplinary Oncology and Therapeutic Innovations Dept, Marseille, France. ${ }^{2}$ Aix Marseille University, Inserm U911 CRO2, Marseille, France.

Correspondence: Céline Mascaux, Service d'Oncologie Multidisciplinaire et Innovations Therapeutiques, Hôpital Nord, Chemin des Bourrely, 13915 Marseille Cedex, France. E-mail: celine.mascauxdap-hm.fr

@ERSpublications

Herein we review personalised medicine for nonsmall cell lung cancer http://ow.ly/LiiI30fXUlJ

Cite this article as: Mascaux C, Tomasini P, Greillier L, et al. Personalised medicine for nonsmall cell lung cancer. Eur Respir Rev 2017; 26: 170066 [https://doi.org/10.1183/16000617.0066-2017].

ABSTRACT After years of standard care prescribed to cancer patients without any selection except the primary site and histology of the tumour, the era of precision medicine has revolutionised cancer care. Personalised medicine refers to the selection of patients for specific treatment based on the presence of specific biomarkers which indicate sensitivity to corresponding targeted therapies and/or lower toxicity risk, such that patients will have the greatest chance of deriving benefit from the treatments. Here, we review personalised medicine for nonsmall cell lung cancer.

\section{Introduction}

Lung cancer is the leading cause of cancer-related mortality among men and women worldwide. Nonsmall cell lung cancer (NSCLC), the most common subtype (85\% of lung cancers), has an overall 5-year survival rate of $16 \%$, which has not improved significantly for several decades [1]. The poor prognosis of lung cancer could be attributed to the diagnosis of the disease at an advanced stage (only 15\% of cases are diagnosed at early stages) and the lack of a cure, as well as the very short survival for patients with advanced stages of NSCLC. Until recently, NSCLCs were all treated similarly, based on staging. Surgery alone was the standard of care for patients with stage I-IIIA NSCLC, resulting in survival rates ranging from $23 \%$ in stage IIIA, to $33 \%$ in stage IIB and up to $89 \%$ in stage IA [2]. Adjuvant chemotherapy after surgical resection of localised NSCLC improves survival at 5 years by $\sim 5 \%$ and is recommended in all resected cases except stage IA [3]. Stage IIIB NSCLCs are generally treated by a combination of thoracic radiotherapy and platinum-based chemotherapy [4]. Until very recently, any stage IV NSCLC patients were exclusively treated by chemotherapy without selection of patients for histology or any other biomarker. In the past 10 years, the therapeutic arsenal for NSCLCs has diversified significantly, with the

Previous articles in this series: No. 1: Chung KF. Personalised medicine in asthma: time for action. Eur Respir Rev 2017; 26: 170064. No. 2: Bonsignore MR, Suarez Giron MC, Marrone O, et al. Personalised medicine in sleep respiratory disorders: focus on obstructive sleep apnoea diagnosis and treatment. Eur Respir Rev 2017; 26: 170069.

Received: June 012017 | Accepted after revision: Sept 012017

Conflict of interest: Disclosures can be found alongside this article at err.ersjournals.com

Provenance: Commissioned article, peer reviewed.

Copyright OERS 2017. ERR articles are open access and distributed under the terms of the Creative Commons Attribution Non-Commercial Licence 4.0. 
emergence of targeted therapies and, more recently, immunotherapies. The concept of personalised medicine has grown with the integration of predictive biomarkers, giving the potential to identify patients who may experience the lowest toxicity and/or derive the greatest benefit from treatments such as chemotherapy and immunotherapy, or personalised treatment based on individual tumour profiling. From the year 2000 onwards, personalised medicine has integrated routine best practice for lung cancer patients with advanced stage disease. Here, we review the current personalised medicine strategies for NSCLC patients.

\section{Personalised medicine based on histology}

Historically, the first step towards personalised medicine in NSCLC has been treatment allocation according to histological type. In the early 2000s, the standard of care in patients with advanced NSCLC and good performance status (score $0-1$ ) was chemotherapy combining a platinum compound (cisplatin or carboplatin) with a third-generation drug such as gemcitabine, vinorelbine or a taxane compound (docetaxel or paclitaxel) [5]. When compared head to head in phase III studies, these doublets have shown comparable efficacy, with some differences in toxicity profiles [6-9]. Then, a randomised non-inferiority phase III study compared cisplatin/pemetrexed to cisplatin/gemcitabine in chemotherapy-naive patients with stage IIIB or IV NSCLC and a performance status of $0-1$ [10]. For the whole study population, overall survival for cisplatin/pemetrexed was non-inferior to cisplatin/gemcitabine (median survival 10.3 months versus 10.3 months, respectively; hazard ratio (HR) 0.94 , 95\% CI 0.84-1.05). However, when outcome was assessed according to histological types, overall survival was significantly longer with cisplatin/pemetrexed than with cisplatin/gemcitabine in the subgroup of patients with adenocarcinoma (12.6 months versus 10.9 months; HR 0.84 , 95\% CI $0.71-0.99$; $\mathrm{p}=0.03$ ) and in the subgroup of patients with large cell carcinoma (10.4 months versus 6.7 months; HR 0.67, 95\% CI 0.48-0.96; p=0.03). In contrast, in the subgroup of patients with squamous cell carcinoma, overall survival was significantly shorter with cisplatin/pemetrexed than with cisplatin/gemcitabine (9.4 months versus 10.8 months; HR 1.23, 95\% CI 1.00-1.51; $\mathrm{p}=0.05$ ). Despite several methodological issues (no central review of histology, up to $30 \%$ of cytological diagnosis, etc.) and unanswered questions (lack of difference in terms of progression-free survival (PFS), impact of thymidilate synthase expression on treatment efficacy, etc.), these results were confirmed by a treatment-by-histology interaction analysis $(p=0.0011)$, and also by a combined analysis of three phase III trials [11]. The combination of cisplatin and pemetrexed was thus approved for first-line treatment of advanced NSCLC, but restricted to nonsquamous histologies. The same restriction subsequently applied to pemetrexed monotherapy, in the setting of second-line treatment $[12,13]$ and maintenance therapy $[14,15]$.

Bevacizumab, an anti-vascular endothelial growth factor (VEGF) monoclonal antibody, was initially assessed in chemotherapy-naive patients with advanced NSCLC in a randomised phase II study [16], comparing carboplatin/paclitaxel alone versus the same chemotherapy plus bevacizumab $15 \mathrm{mg} \cdot \mathrm{kg}^{-1}$ or $7.5 \mathrm{mg} \cdot \mathrm{kg}^{-1}$. The efficacy of the combination was superior to the chemotherapy alone regarding objective response rate (ORR), PFS and overall survival. The tolerance was characterised by new safety issues and especially the development of hypertension, proteinuria and bleeding events, including grade 5 pulmonary haemorrhages, predominantly in squamous NSCLC patients, who were therefore excluded from subsequent trials. Therefore, a first phase III randomised trial (ECOG4599) randomised previously untreated stage IV NSCLC patients between carboplatin/paclitaxel for six cycles versus the same chemotherapy regimen plus bevacizumab $15 \mathrm{mg} \cdot \mathrm{kg}^{-1}$ until progression [17], the combination being significantly superior to the chemotherapy alone. Another phase III randomised trial (AVAiL) [18], blinded regarding the use of the bevacizumab, compared a "European" chemotherapy regimen (i.e. cisplatin/gemcitabine) alone or with bevacizumab $\left(7.5 \mathrm{mg} \cdot \mathrm{kg}^{-1}\right.$ and $\left.15 \mathrm{mg} \cdot \mathrm{kg}^{-1}\right)$ and again found the combination significantly superior to the chemotherapy alone regarding ORR and PFS, but not overall survival [19]. Altogether, these two phase III studies (summarised in table 1) led to the approval of bevacizumab in combination with first-line platinum-based chemotherapy for stage IV NSCLC patients, but with nonsquamous histologies only.

Necitumumab, an anti-epidermal growth factor receptor (EGFR) monoclonal antibody, was assessed in two phase III trials with similar designs in patients with NSCLC, according to histological type. First, in the INSPIRE trial, conducted in previously untreated, stage IV nonsquamous NSCLC [20], patients received either the cisplatin/pemetrexed doublet alone, or with necitumumab. Enrolment in this trial was stopped after 633 patients had enrolled, following an independent data monitoring committee recommendation based on an observed imbalance in fatal thromboembolic events between the two arms. There was no significant difference in overall survival (primary end-point), PFS, ORR and disease control rate between treatment groups. The SQUIRE phase III trial, conducted in patients with squamous cell carcinoma using cisplatin/gemcitabine [21], met its primary objective with a significant improvement of 


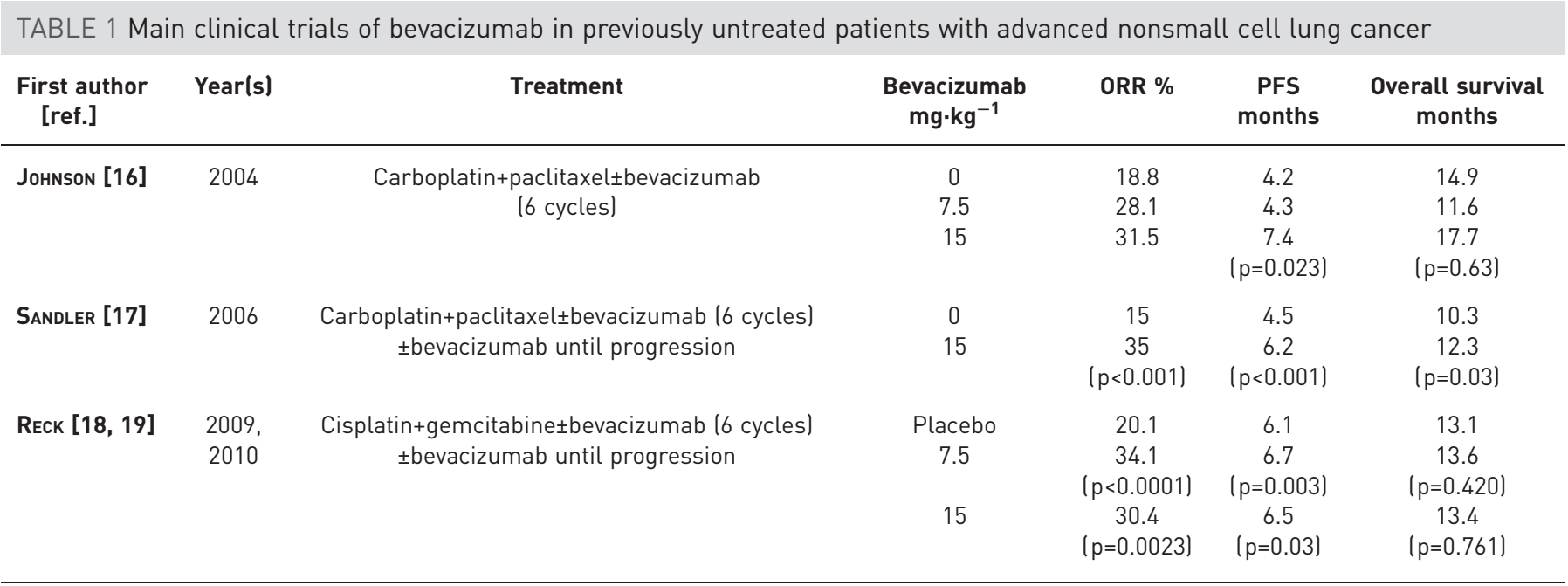

ORR: objective response rate; PFS: progression-free survival.

overall survival in the experimental arm (11.5 months versus 9.9 months; HR $0.84,95 \%$ CI $0.74-0.96$; $\mathrm{p}=0.01$ ). Based on these results, the approval of necitumumab has been restricted to squamous NSCLC.

Nintedanib is a triple angiokinase inhibitor that simultaneously inhibits signalling pathways activated by VEGF, fibroblast growth factor and platelet-derived growth factor. The LUME-Lung randomised phase III trial [22] showed a significantly improved PFS in the nintedanib/docetaxel group compared with the placebo/docetaxel group (3.4 months versus 2.7 months; HR 0.79, 95\% CI 0.68-0.92; $\mathrm{p}=0.0019$ ). Overall survival was significantly improved for patients in the experimental arm in all patients with adenocarcinoma (12.6 months versus 10.3 months; HR 0.83 , 95\% CI $0.70-0.99 ; \mathrm{p}=0.0359$ ) and in a predefined group of patients with adenocarcinoma and poor prognosis (10.9 months versus 7.9 months; HR 0.75, 95\% CI 0.60-0.92; p=0.0073). Finally, in all patients, regardless of histology, overall survival did not significantly differ between the two arms. These results led to the approval of nintedanib, in combination with docetaxel, as second-line treatment for advanced NSCLC, but only in patients with adenocarcinoma histology.

\section{Personalised medicine based on tumour molecular profile EGFR mutations}

EGFR is a transmembrane receptor protein with tyrosine kinase activity, against which specific tyrosine kinase inhibitors (TKIs) have been developed. First evaluated in previously treated patients with NSCLC $[23,24]$, EGFR TKIs were then evaluated in combination with chemotherapy $[25,26]$, but did not improve the outcome compared to chemotherapy alone. In 2005, lung cancer care was revolutionised by the discovery that activating mutations in the tyrosine kinase domain of EGFR cause sensitivity to the effect of EGFR TKIs in patients with NSCLC [27]. The EGFR mutations are located in exons 18, 19, 20 and 21, but the large majority of sensitising mutations of EGFR are deletions of exon 19 (most frequently delE746-A750) and point mutations of exon 21 (L858R). The discovery of EGFR as an oncogenic driver and the identification of its mutation as a predictor of the response to EGFR TKIs dramatically changed lung cancer treatment, because it offered the first opportunity for bioguided targeted therapy. The two first EGFR TKIs to be developed were gefitinib and erlotinib. MoK et al. [28] published the first data showing an advantage of using biomarker-guided therapy. Gefitinib provided a better outcome than chemotherapy to patients with NSCLC harbouring an EGFR-activating mutation. The ORR to gefitinib was $71 \%$ and the PFS was 9.5 months in patients with advanced NSCLC that harboured an EGFR-activating mutation, thus showing a very significantly better outcome (HR 0.48, p<0.001) compared to standard chemotherapy, which had an ORR of $47 \%$ and a PFS of 6.3 months. Inversely, chemotherapy was more favourable than gefitinib in the group of patients without activating mutations of EGFR (HR 2.85, p <0.001). Subsequently, several other randomised trials with erlotinib or gefitinib confirmed the superiority of first-line treatment with first-generation EGFR TKIs compared with chemotherapy for patients with advanced EGFR-mutated NSCLC tumours (table 2) [29-33]. These two drugs were thus approved and recommended for this indication. Subsequently, afatinib, a second-generation EGFR TKI, also showed similar benefit compared to chemotherapy in NSCLC with EGFR-activating mutations in several randomised studies. Gefitinib, erlotinib and afatinib have been approved and are recommended in first-line therapy in advanced NSCLC with activating mutations in the tyrosine kinase domain of EGFR (tables 2 and 3) [34, 35]. 
TABLE 2 Phase III randomised trials comparing EGFR TKIs with chemotherapy in first-line therapy in EGFR-mutant nonsmall cell lung cancer

\begin{tabular}{|c|c|c|c|c|c|c|c|}
\hline $\begin{array}{l}\text { First author } \\
\text { [ref.] }\end{array}$ & $\begin{array}{l}\text { Study } \\
\text { name }\end{array}$ & Ethnicity & $\begin{array}{c}\text { Patients with EGFR } \\
\text { mutation } \mathrm{n}\end{array}$ & EGFR TKI & Chemotherapy & $\begin{array}{c}\text { ORR }^{\#} \\
\%\end{array}$ & $\begin{array}{c}\text { PFS } \\
\text { months }\end{array}$ \\
\hline Mok [28] & IPASS & Asians & 261 & $\begin{array}{l}\text { Gefitinib } \\
\text { (n=132) }\end{array}$ & $\begin{array}{l}\text { Carboplatin/paclitaxel } \\
\qquad(\mathrm{n}=129)\end{array}$ & $71 / 47$ & $\begin{array}{c}9.5 / 6.3 \\
\text { (HR } 0.48)\end{array}$ \\
\hline Mitsudomi [29] & WJTOG3405 & Asians & 117 & $\begin{array}{c}\text { Gefitinib } \\
(n=58)\end{array}$ & $\begin{array}{c}\text { Cisplatin/docetaxel } \\
(n=59)\end{array}$ & $62 / 32$ & $\begin{array}{r}98.2 / 6.3 \\
\text { (HR 0.49) }\end{array}$ \\
\hline Zнои [31] & OPTIMAL & Asians & 154 & $\begin{array}{l}\text { Erlotinib } \\
\text { (n=82) }\end{array}$ & $\begin{array}{l}\text { Carboplatin/gemcitabine } \\
\qquad(\mathrm{n}=72)\end{array}$ & $83 / 36$ & $\begin{array}{r}13.1 / 4.6 \\
\text { (HR } 0.37 \text { ) }\end{array}$ \\
\hline RoselL [32] & EURTAC & Caucasians & 173 & $\begin{array}{l}\text { Erlotinib } \\
\qquad(n=86)\end{array}$ & $\begin{array}{l}\text { Doublets with platinum } \\
\qquad(\mathrm{n}=87)\end{array}$ & $71 / 47$ & $\begin{array}{c}9.58 / 5.5 \\
\text { (HR 0.37) }\end{array}$ \\
\hline Wu [35] & LUX-Lung 6 & Asians & 364 & $\begin{array}{l}\text { Afatinib } \\
(n=242)\end{array}$ & $\begin{array}{l}\text { Cisplatin/gemcitabine } \\
\qquad(\mathrm{n}=122)\end{array}$ & $67 / 23$ & $\begin{array}{r}11.0 / 5.6 \\
\text { (HR 0.28) }\end{array}$ \\
\hline
\end{tabular}

EGFR: epidermal growth factor receptor; TKI: tyrosine kinase inhibitor; ORR: objective response rate; PFS: progression-free survival; HR: hazard ratio. ${ }^{\#}$ : comparisons presented as EGFR TKI/chemotherapy.

Although initial response or disease stabilisation are generally observed for about 11 months with one of these three drugs in first-line therapy, all patients with NSCLC harbouring EGFR mutations will eventually become resistant and disease will progress. The mechanism of resistance to first-line EGFR TKIs has been studied and identified. The most frequent acquired mechanism of resistance to first-line EGFR TKIs is the T790M mutation in exon 20 of EGFR [36]. It is detected in $>50 \%$ of cases of secondary resistance to EGFR TKIs, but can also exist de novo. Other secondary mechanisms of resistance acquired with first-/ second-generation EGFR TKIs have been discovered: the activation of bypass pathways (by KRAS mutations, $c-M E T$ amplification or HER2 amplification), the mesenchymal-epithelial transition, the high expression of insulin-like growth factor receptor 1 (IGF1R), BIM (B-cell lymphoma-2-like 11 gene) polymorphisms or the histological transformation into small cell lung cancer. Osimertinib, a third-generation EGFR TKI, has shown an ORR of 77\% and PFS of 10.1 months in patients with NSCLC habouring a T790M mutation and was found to be significantly superior to chemotherapy in these patients (HR 0.30, p<0.001) [37]. Osimertinib is now approved and recommended after first-line EGFR TKIs in the presence of the T790M mutation. For the other mechanisms of resistance, no specific treatment is recommended other than chemotherapy, i.e. the combination of cisplatin and pemetrexed for

TABLE 3 Currently approved targeted therapies in nonsmall cell lung cancer along with their target

\begin{tabular}{lcc} 
Drug & Target & Line \\
\hline Erlotinib & EGFR sensitising mutation & 1 \\
Gefitinib & EGFR sensitising mutation & 1 \\
Afatinib & $E G F R$ sensitising mutation & 1 \\
Osimertinib & $E G F R$ T790M mutation & $1+$ \\
Crizotinib & $A L K / R O S 1$ & 1 \\
Ceritinib & $A L K$ & 2 \\
Dabrafenib+trametinib & $B R A F$ & 1 \\
\hline
\end{tabular}

EGFR: epidermal growth factor receptor; ALK: anaplastic lymphoma kinase. 
adenocarcinomas and the classical association of cisplatin and etoposide in the case of transformation in small cell lung cancer. However, it is possible to prescribe specific inhibitors of the receptor tyrosine kinase MET, i.e. crizotinib, in the context of clinical trials when MET is amplified.

\section{Anaplastic lymphoma kinase rearrangements}

Initially discovered as a translocation in anaplastic large-cell lymphomas, gene rearrangement involving the anaplastic lymphoma kinase (ALK) was identified in lung cancer in 2007 and was subsequently found to predict very high sensitivity to crizotinib [38]. As for EGFR TKIs for EGFR-mutated NSCLC, crizotinib results are better than chemotherapy when used in second-line therapy after platinum doublet (ORR 65\% versus 20\%, $\mathrm{p}<0.001$; and PFS 7.7 months versus 3.0 months, HR 0.49, $\mathrm{p}<0.001$ ) [39] and in first-line therapy (ORR 74\% versus 45\%, $<<0.001$; and PFS 10.9 months versus 7.0 months, HR $0.45, \mathrm{p}<0.001$ ) in patients with $A L K$-rearranged NSCLC [40]. Consequently, crizotinib is recommended in a first-line setting for patients with advanced NSCLC with $A L K$ rearrangements.

Cure has not been obtained with crizotinib either, and all patients also ultimately progress after $\sim 10$ months of disease control. Resistance mechanisms in patient with ALK-rearranged NSCLC treated by crizotinib have been studied and are found to be either ALK-related or not. In the first case, secondary ALK mutations that confer acquired resistance to crizotinib, such as L1152R, C1156Y, F1174L, L1196M, L1198P, D1203N, G12102R and G1269A, as well as ALK amplifications have been reported [41]. Activations of bypass pathways, i.e. by EGFR and KRAS mutations or MET amplifications, are also responsible for acquired resistance to crizotinib in patients with $A L K$-rearranged NSCLC. Several second-generation ALK TKIs have been developed. Alectinib and ceritinib, when used in patients previously treated with crizotinib, showed ORRs of $48 \%$ and $56 \%$, respectively [42, 43]. Notably, the cumulative PFS of patients with ALK-rearranged NSCLC who received crizotinib followed by alectinib or ceritinib at resistance reached $\sim 50$ months.

Afterwards, patients also develop resistance to these second-generation ALK inhibitors, e.g. by the acquisition of new mutations in $A L K$, some being drug-specific, such as F1174C/V and G1202del with ceritinib or I1171T/N/S and V1180L with alectinib, and other mutations being common to both drugs, such as G1202R [44]. Brigatinib, another second-generation ALK inhibitor, showed results similar to those of alectinib and ceritinib in patients previously treated with crizotinib: ORR was $71 \%$ and PFS 12.3 months [45]. Patients treated with brigatinib will also develop the G1202R mutation as well as specific resistance mutations in $A L K$, e.g. E1210K+S1206C or E1210K+D1203N [44]. Most recently, lorlatinib has been shown to inhibit ALK and has attracted a great deal of interest as it has activity against the G1202R mutation developed secondarily with all the other drugs. It also has a very high penetration into the central nervous system [44]. Again, new mutations of resistance in $A L K$ occur with lorlatinib treatment (C1156Y $+\mathrm{L} 1198 \mathrm{~F}$ mutations) [44]. Ceritinib and alectinib are currently recommended in guidelines for second-line therapy after progression to crizotinib in advanced NSLCLC with $A L K$ rearrangement, independently of the resistance mechanism [46]. Brigatinib may be approved shortly for the same indication. In the future, it may also become indicated to select second- and third-line therapy based on the resistance mechanism, particularly as lorlatinib is the only ALK inhibitor with activity against the G1202R-mutated ALK NSCLC.

In addition, second-generation ALK TKIs, initially studied in patients who failed in response to first-line crizotinib, may move to the first-line setting. The ASCEND-4 trial showed an ORR of $73 \%$ versus $27 \%$ and a doubled PFS of 16.6 months versus 8.1 months for ceritinib versus chemotherapy groups, respectively (HR 0.55, p<0.00001), as first-line therapy too [47]. The ORR and PFS with ceritinib appear superior in first-line compared with crizotinib for ALK-rearranged NSCLC; however, this study did not provide a direct comparison between ceritinib and crizotinib. However, the J-ALEX trial, performed in an Asian cohort, showed an ORR of $85.4 \%$ versus $70.2 \%$ with alectinib and crizotinib, respectively, and significantly improved PFS with alectinib (HR 0.34, 95\% CI 0.17-0.71) in first-line therapy for patients with ALK-rearranged NSCLC [48]. More recently, the ALEX trial showed a very significant benefit of using alectinib in first-line therapy as compared with crizotinib (PFS HR 0.47, 95\% CI 0.34-0.65). Interestingly, alectinib also significantly delayed the time to central nervous system progression compared with crizotinib, with an incidence of brain progression at 12 months of $9.4 \%$ versus $41.4 \%$, respectively (HR 0.16, 95\% CI 0.10-0.28) [49]. Thus, second-generation ALK inhibitors, i.e. ceritinib and alectinib, may be prescribed in the first-line setting in the future and this may change the profile of resistance of patients with $A L K$-rearranged lung tumours, in terms of delay and type of mechanism. A summary of the main studies testing targeted therapies in NSCLC with ALK rearrangement is presented in table 4.

\section{ROS1 rearrangements}

First described in glioblastomas and cholangiocarcinomas, ROS1 is a receptor of the insulin receptor family with tyrosine kinase activity. More recently, rearrangements of the ROS1 gene have occasionally 
been identified in NSCLC (1-2\%) [42, 50]. ALK and ROS1 tyrosine kinase domains have a high similarity, so crizotinib was tested on NSCLC harbouring ROS1 rearrangement and showed ORRs of $72 \%$ and $80 \%$ and PFSs of 19.2 months and 9.1 months, in a cohort from the USA [51] and in a European cohort [50], respectively. In the Asian Open-Label phase II study, ceritinib also benefited heavily pretreated patients with NSCLC harbouring ROS1 rearrangement. Among the 28 patients that were evaluable for response, the ORR was $62 \%$. Of the eight patients with brain metastases, intracranial disease control was $63 \%$. The median PFS was 9.3 months for all patients and 19.3 months for crizotinib-naive patients [52].

\section{Emerging molecular targets}

Other targetable oncogenic drivers have also been identified, including RET fusions, MET amplification, MET exon 14 splice junction mutations, BRAF mutations and HER2 mutations. New targeted therapies have been developed and are currently being evaluated worldwide for these new drivers. In patients with RET fusion tumours, studies of small cohorts of patients have been recently reported with ORRs of $28-37 \%, 18-53 \%$ and $22 \%$ for cabozantinib, vandetanib and sunitinib, respectively [53-55]. Alectinib is potentially active on NSCLC with RET fusions as well, with two responses among four patients treated [56]. Patients with NSCLC with MET amplifications may benefit from treatment with crizotinib [57, 58]. More recently, a splice-site mutation of MET was identified. This mutation is responsible for the loss of exon 14 of MET and Cbl-binding site on the MET receptor protein. Consequently, degradation of the MET receptor is reduced and its expression level is increased. NSCLCs with a MET exon 14 splice mutation also experience a dramatic clinical response to crizotinib [59]. For NSCLC patients with V600E mutations of $B R A F$, several therapeutic options exist: dabrafenib in monotherapy (ORR 33\%), dabrafenib in combination with trametinib (ORR 63.2\%) and verumafinib in monotherapy (ORR 42\%) [60-63]. In NSCLC patients with BRAF V600E mutations, the US Food and Drug Administration (FDA) and the European Medicines Agency have approved the combination of dabrafenib and trametinib, and it thus has become a standard treatment. Trastuzumab [64] and afatinib [65] may be proposed for patients with NSCLC harbouring HER2 mutations, although these treatments are less effective than usually observed with targeted therapies for oncogenic drivers.

TABLE 4 Main trials published with targeted therapies in nonsmall cell lung cancer with ALK rearrangement

\begin{tabular}{|c|c|c|c|c|c|c|c|c|}
\hline $\begin{array}{l}\text { First author } \\
\text { [ref.] }\end{array}$ & Year & Phase & $\begin{array}{l}\text { Treatment } \\
\text { setting }\end{array}$ & $\begin{array}{l}\text { Previous ALK } \\
\text { inhibitor }\end{array}$ & ALK TKI & $\begin{array}{c}\text { Comparison } \\
\text { therapy }\end{array}$ & ORR ${ }^{\#} \%$ & $\begin{array}{l}\text { PFS } \\
\text { months }\end{array}$ \\
\hline SoLomon [40] & 2014 & III & First-line & No & Crizotinib (n=172) & $\begin{array}{l}\text { Platinum doublet } \\
\qquad(n=171)\end{array}$ & $74 / 45$ & $\begin{array}{l}10.9 / 7.0 \\
\text { (HR 0.45) }\end{array}$ \\
\hline $\begin{array}{l}\text { SoRIA [47] } \\
\text { (ASCEND-4) }\end{array}$ & 2017 & III & First-line & No & Ceritinib $(n=189)$ & $\begin{array}{l}\text { Platinum doublet } \\
\qquad(n=187)\end{array}$ & $73 / 27$ & $\begin{array}{c}16.6 / 8.1 \\
\text { (HR 0.55) }\end{array}$ \\
\hline $\begin{array}{l}\text { Peters [49] } \\
\text { (ALEX) }\end{array}$ & 2017 & III & First-line & No & Alectinib (n=152) & $\begin{array}{c}\text { Crizotinib } \\
(n=151)\end{array}$ & $83 / 76$ & $\begin{array}{c}\text { Not reached/ } \\
11.1 \\
\text { (HR 0.47) }\end{array}$ \\
\hline SHAW [39] & 2013 & III & Second-line & No & Crizotinib ( $n=173$ ) & $\begin{array}{l}\text { Pemetrexed } \\
\qquad(n=174)\end{array}$ & $65 / 20$ & $\begin{array}{c}7.7 / 3.0 \\
\text { (HR 0.49) }\end{array}$ \\
\hline SHAW [43] & 2016 & $\|$ & Any lines & Crizotinib & Alectinib $(n=69)$ & & 48 & 8.1 \\
\hline Gettinger [45] & 2016 & $1 / I 1$ & $\begin{array}{l}\text { Any lines } \\
\text { Any lines } \\
\text { Any lines } \\
\text { Any lines }\end{array}$ & $\begin{array}{c}\text { Accepted } \\
\text { No } \\
\text { Crizotinib } \\
\text { Accepted but brain } \\
\text { metastasis }\end{array}$ & $\begin{array}{c}\text { Brigatinib }(n=52) \\
\text { Brigatinib }(n=4) \\
\text { Brigatinib }(n=52) \\
\text { Brigatinib }(n=6)\end{array}$ & & $\begin{array}{c}77 \\
100 \\
74 \\
83\end{array}$ & $\begin{array}{c}\text { Not reached } \\
14.5 \\
\text { No event }\end{array}$ \\
\hline
\end{tabular}

ALK: anaplastic lymphoma kinase; TKI: tyrosine kinase inhibitor; ORR: objective response rate; PFS: progression-free survival; HR: hazard ratio. " : comparisons presented as ALK TKI/comparison therapy. 
The master enemy: KRAS mutations

KRAS mutations are detected in up to $32 \%$ of NSCLCs at diagnosis, mainly in lung adenocarcinoma and in smokers [66]. KRAS mutations are associated with a poor prognosis [67] and result more frequently in brain metastasis compared with lung adenocarcinomas without these mutations [68]. Usually, KRAS mutations in NSCLC are single amino acid substitutions in codon 12 of exon 2 and less commonly in codon 13 of exon $2(\sim 10 \%)$. Currently, international guidelines recommend treating KRAS-mutant lung adenocarcinomas with chemotherapy, i.e. a platinum doublet, as efficient targeted therapies against KRAS mutations are not available [69]. Many drugs acting at different levels of KRAS pathways have been tested without showing any significant benefit. Drugs tested in KRAS-mutant NSCLC have failed to improve the prognosis so far; these include farnesyl transferase inhibitors, several MEK inhibitors, PI3K inhibitors, mTOR inhibitors, MET inhibitors, Hsp90 inhibitors and CDK4/6 inhibitors [69]. In addition, KRAS is difficult to target directly. Specific inhibitors of the G12C KRAS mutant are only in development [70]. Clinical benefits have not yet been demonstrated and, even if they are, the large majority of KRAS mutations would remain without a direct inhibitor.

\section{Recommendation for molecular testing}

First-line setting

As routine practice, testing for EGFR mutations, BRAF mutations and rearrangements of $A L K$ and ROS1 must be performed at diagnosis to choose the appropriate first-line therapy in all patients with advanced pure lung adenocarcinomas or an adenocarcinoma component in mixed tumours. Pure squamous cell carcinoma patients and those with neuroendocrine tumours are usually not tested for molecular biomarkers. However, pure lung squamous cell carcinomas with clinical features that are associated with high risk for EGFR/ALK/ROS1 aberrations (e.g. never/light smokers) should also be tested. To standardise biomarker testing in lung cancer, the College of American Pathologists, the International Association for Study of Lung Cancer and the Association of Molecular Pathologists have published guidelines [71] that recommend, at diagnosis, that all advanced NSCLC patients with an adenocarcinoma or a tumour with an adenocarcinoma component should be tested for EGFR mutations, ALK rearrangements and ROS1 fusions, using the most accessible tissue (primary tumour or metastasis). Similar recommendations have been published by other scientific societies, including the American Society of Clinical Oncology [72], the National Comprehensive Cancer Network (in the USA) [73] and the European Society for Medical Oncology [46], for their own guidelines. Since the publication of these guidelines, the search for BRAF mutations should be added as there is an FDA-approved treatment for such patients. In addition, RET fusions, MET amplifications, MET exon 14 splicing mutations and HER2 mutations should be searched for in all patients with advanced NSCLC, with an adenocarcinoma component or light smoking habits, who were found negative for EGFR, ALK, ROS1 and BRAF testing. Of note, these secondary tests may be performed in parallel when there is no concern about tissue availability and multiplex panels will be utilised increasingly for EGFR, ALK, ROS1, RET, BRAF, HER2 and MET testing in patients with NSCLC, as they are more cost-benefit effective than successive single-gene analyses, being cheaper and requiring less time and tissue.

\section{Second-line setting}

At resistance after first-line therapy with EGFR TKI for patients with advanced NSLCLC harbouring activating mutations of EGFR, repeating molecular testing on a fresh biopsy, ideally sampled at the progressing site when technically feasible, is recommended, and osimertinib should be prescribed for patients if the T790M mutation of EGFR is detected. However, tissue rebiopsy may be clinically challenging and results in a $35 \%$ failure rate overall, including an inability to obtain tissue and non-contributive biopsies. Obtaining a surrogate sample to detect molecular abnormalities by means of a noninvasive approach is thus required, e.g. so-called liquid biopsies, implying genomic testing on cell-free DNA from peripheral blood. T790M detection in the circulating tumour DNA (ctDNA) has shown a sensitivity of $40-80 \%$ and specificity of $95-100 \%$, depending on the technique being used [74]. As the sensitivity is relatively low, false-negative results occur frequently. Thus, liquid biopsy is recommended as a first option to detect EGFR T790M mutations at the time of acquired resistance to first-line EGFR TKIs [75]. However, because of the low sensitivity, any negative results on the ctDNA testing in the blood should lead to tissue rebiopsy and EGFR testing in the tumour sample. Recently, the FDA has approved EGFR mutation ctDNA testing at frontline and at relapse for T790M, by using the cobas ${ }^{\circledast}$ EGFR Mutation Test v2 (Roche Molecular Diagnostics, Pleasanton, CA, USA).

Of note, after treatment with first-line crizotinib ALK inhibitors in patients with advanced NSCLC with $A L K$ rearrangements, testing for the mechanism of resistance, i.e. ALK mutations, is currently not recommended for a treatment decision. 


\section{Personalised medicine based on immune profile}

Anti-tumour immunity was first described more than 100 years ago. It relies both on innate immunity and adaptive immunity [76]. Adaptive immunity is divided into two phases: the priming phase, where dendritic cells interact with T-cells, and the effector phase, where T-cells interact with cancer cells [77]. These two phases involve activating signals and inhibitory signals. In the priming phase, inhibitory signals rely on CTLA-4 (cytotoxic T lymphocyte antigen 4), expressed by T-cells, whereas in the effector phase, inhibitory signals rely on PD-1 (programmed cell death 1), expressed by T-cells, and PD-L1 (programmed cell death ligand 1), expressed by cancer cells. Lung cancer cells are able to avoid anti-tumour immunity via several mechanisms, including activation of these inhibitory signals [78]. A better knowledge of anti-tumour immunity biology and of the mechanisms used by cancer cells to avoid the immune system has led to the development of immunotherapy drugs.

Immunotherapy in lung cancer first started with the development of anti-cancer vaccines. Several vaccines (anti-MAGE-A3, anti-BLP25, belagenpumatucel-L) have been studied in phase III clinical trials, but none of them demonstrated any efficacy in the treatment of NSCLC patients [79-81]. Later, based on adaptive immunity mechanisms, immune checkpoint inhibitors (ICIs) were developed to target anti-cancer immunity inhibitory signals. Although the anti-CTLA-4 monoclonal antibodies ipilimumab and tremelimumab showed promising results in combination with chemotherapy or in the maintenance setting after first-line chemotherapy, they were not approved for the treatment of NSCLC [76, 82]. PD-1 inhibitors were the first ICIs to receive FDA approval for NSCLC. Both nivolumab and pembrolizumab improved overall survival and reduced toxicity in comparison with docetaxel chemotherapy in the second-line treatment of NSCLC in phase III clinical trials [83-85] and are approved in this setting. They were also studied in the first-line setting. While pembrolizumab [86] improved outcomes in comparison with chemotherapy and is FDA-approved, nivolumab [87] failed to show any survival improvement in first-line NSCLC treatment in phase III trials. Furthermore, atezolizumab, a PD-L1 inhibitor, also showed an overall survival improvement in comparison with docetaxel in the second-line setting in a phase III clinical trial [88] and also received FDA approval. The results of phase III clinical trials are reported in table 5.

Consequently, the recent development of ICIs has revolutionised the treatment of advanced NSCLC, offering new treatment options approved in the second-line setting. However, ICIs do not fit to every

TABLE 5 Phase III randomised trials of PD-1 and PD-L1 inhibitors showing efficacy results and the technologies used for PD-L1 testing

\begin{tabular}{|c|c|c|c|c|c|c|c|c|c|c|c|c|}
\hline & \multicolumn{2}{|c|}{$\begin{array}{c}\text { CheckMate } \\
017 \text { [83] }\end{array}$} & \multicolumn{2}{|c|}{$\begin{array}{c}\text { CheckMate } \\
057[84]\end{array}$} & \multicolumn{2}{|c|}{$\begin{array}{c}\text { CheckMate } \\
026[87]\end{array}$} & \multicolumn{2}{|c|}{$\begin{array}{l}\text { Keynote } \\
010[85]\end{array}$} & \multicolumn{2}{|c|}{$\begin{array}{l}\text { Keynote } \\
024[86]\end{array}$} & \multicolumn{2}{|c|}{$\begin{array}{l}\text { OAK } \\
{[88]}\end{array}$} \\
\hline Population & \multicolumn{2}{|c|}{$\begin{array}{c}\text { sNSCLC } \\
\geqslant \text { Second-line }\end{array}$} & \multicolumn{2}{|c|}{$\begin{aligned} & \text { nsNSCLC } \\
\geqslant & \text { Second-line }\end{aligned}$} & \multicolumn{2}{|c|}{$\begin{array}{l}\text { PD-L1 } \geqslant 1 \% \\
\text { First-line }\end{array}$} & \multicolumn{2}{|c|}{$\begin{array}{c}\text { PD-L1 } \geqslant 1 \% \\
\geqslant \text { Second-line }\end{array}$} & \multicolumn{2}{|c|}{$\begin{array}{l}\text { PD-L1 } \geqslant 50 \% \\
\text { First-line }\end{array}$} & \multicolumn{2}{|c|}{$\begin{array}{c}\text { NSCLC } \\
\geqslant \text { Second-line }\end{array}$} \\
\hline Drug & Nivo & Doce & Nivo & Doce & Nivo & Chemo & Pembro & Doce & Pembro & Chemo & Atezo & Doce \\
\hline ORR \% & 20 & 9 & 19 & 12 & 26.1 & 33.5 & 18 & 9 & 44.8 & 27.8 & 14 & 13 \\
\hline PFS months & 3.5 & 2.8 & 2.3 & 4.2 & 4.2 & 5.9 & $3.9,4.0^{\#}$ & 4.0 & 10.3 & 6.0 & 2.8 & 4.0 \\
\hline \multicolumn{13}{|l|}{ PD-L1 expression } \\
\hline Antibody & \multicolumn{2}{|c|}{$28-8$} & \multicolumn{2}{|c|}{$28-8$} & \multicolumn{2}{|c|}{$28-8$} & \multicolumn{2}{|c|}{$22 \mathrm{C} 3$} & \multicolumn{2}{|c|}{$22 \mathrm{C} 3$} & \multicolumn{2}{|c|}{ SP142 } \\
\hline $\begin{array}{l}\text { Platform } \\
\text { manufacturer }\end{array}$ & \multicolumn{2}{|c|}{ Dako } & \multicolumn{2}{|c|}{ Dako } & \multicolumn{2}{|c|}{ Dako } & \multicolumn{2}{|c|}{ Dako } & \multicolumn{2}{|c|}{ Dako } & \multicolumn{2}{|c|}{ Ventana } \\
\hline Analysed cells & \multicolumn{2}{|c|}{ Tumour cells } & \multicolumn{2}{|c|}{ Tumour cells } & \multicolumn{2}{|c|}{ Tumour cells } & \multicolumn{2}{|c|}{ Tumour cells } & \multicolumn{2}{|c|}{ Tumour cells } & \multicolumn{2}{|c|}{$\begin{array}{l}\text { Tumour and } \\
\text { immune cells }\end{array}$} \\
\hline $\begin{array}{l}\text { Sampling time } \\
\text { Preanalytic }\end{array}$ & $\begin{array}{r}\text { Pretr } \\
\text { Ar } \\
\mathrm{F}\end{array}$ & $\begin{array}{l}\text { tment } \\
\text { ival } \\
\text { E }\end{array}$ & $\begin{array}{r}\text { Pretre } \\
\text { Arc } \\
\end{array}$ & $\begin{array}{l}\text { tment } \\
\text { ival } \\
\text { E }\end{array}$ & $\begin{array}{l}\text { Pret } \\
\text { Arch }\end{array}$ & $\begin{array}{l}\text { atment } \\
\text { al FFPE }\end{array}$ & $\begin{array}{r}\text { Any } \\
\text { Archival o }\end{array}$ & new & $\begin{array}{l}\text { Pretre } \\
\text { Archiva }\end{array}$ & $\begin{array}{l}\text { ment } \\
\text { pr new }\end{array}$ & $\begin{array}{r}\text { Pretr } \\
\text { Arch } \\
r\end{array}$ & $\begin{array}{l}\text { tment } \\
\text { al or } \\
\text { N }\end{array}$ \\
\hline
\end{tabular}

ORR: objective response rate; PFS: progression-free survival; PD-L1: programmed cell death ligand 1; NSCLC: nonsmall cell lung cancer; Nivo: nivolumab; Doce: docetaxel; Chemo: chemotherapy; Pembro: pembrolizumab; Atezo: atezolizumab; FFPE: formalin-fixed paraffin-embedded. ${ }^{\#}$ : two doses of pembrolizumab were tested $\left(2 \mathrm{mg} \cdot \mathrm{kg}^{-1}\right.$ and $\left.10 \mathrm{mg} \cdot \mathrm{kg}^{-1}\right) ;{ }^{9}$ : 6-month overall survival rate. 
patient with advanced NSCLC. For example, approximately half of patients with nonsquamous NSCLC receiving second-line nivolumab will have a progressive disease after the first tumour assessment [84]. Moreover, some patients seem to be more likely to develop immune-related adverse events such as pneumonitis [89]. For these reasons, there is a need to identify biomarkers to predict the efficacy and tolerance of ICIs. The first biomarker studied in this field was the expression of PD-L1. PD-L1 is expressed by cancer cells in order to increase anti-cancer immunity inhibitory signals. It is directly targeted by PD-L1 inhibitors such as atezolizumab but is also a ligand of PD-1, targeted by nivolumab and pembrolizumab. CHAE et al. [90] reported association between ORR and PD-L1 expression data from several clinical trials studying the efficacies of ICIs. In most trials, their efficacy was better for patients with PD-L1-positive tumours. However, phase III studies of anti-PD-1 and anti-PD-L1 reported conflicting results regarding the potential predictive effect of PD-L1 expression (table 5). In the CheckMate 017 study, PD-L1 expression was neither prognostic nor predictive for nivolumab efficacy in squamous NSCLC patients [83], whereas in the CheckMate 057 study nivolumab was associated with a greater efficacy than docetaxel in patients with PD-L1-positive tumours, whatever the threshold (1\%, 5\% or 10\%) [84]. In the pembrolizumab Keynote 010 study, only patients with PD-L1 expression on $\geqslant 1 \%$ tumour cells were enrolled. Overall survival was longer with pembrolizumab in the overall population, but the difference between pembrolizumab and docetaxel was even greater in the subgroup of patients with PD-L1 expression on $\geqslant 50 \%$ of tumour cells [85]. By contrast, in the OAK study, PD-L1 expression by either tumour cells or immune cells was not predictive of atezolizumab efficacy [88]. In the first-line setting, pembrolizumab as monotherapy was only studied in patients whose tumours had a PD-L1 expression level of $>50 \%$ [86]. These differences can be explained by the different technologies used in those phase III clinical trials (table 5). The antibodies and platform chosen for PD-L1 immunohistochemistry were different for each drug in phase III trials. Moreover, while for nivolumab and pembrolizumab PD-L1 expression was tested only on the tumour cell membrane, for atezolizumab, PD-L1 expression was also tested on tumour-infiltrative immune cells. Moreover, pathologists experience difficulties with PD-L1 immunohistochemistry interpretation, especially for cases with focal PD-L1 expression or in small biopsy specimens [91]. Ongoing efforts are being made to harmonise PD-L1 testing, for example in the Blueprint study [92] or the German harmonisation study [93].

Because of the pitfalls of using PD-L1 immunohistochemistry as a biomarker test for ICIs, other immunological biomarkers were also studied. PD-L2 expression has been described in some tumours, but its predictive role for the efficacy of PD-1 and PD-L1 inhibitors has been poorly studied in solid tumours [94]. Preclinical models have also demonstrated the role of $\mathrm{CD}^{+}$cytotoxic T-lymphocytes (CTL) in the anti-tumour adaptive immune system [94]. More recently, CD8 ${ }^{+}$CTL density in the tumour has been correlated with melanoma patients' response to PD-1 inhibitors [95]. For this reason, CD8 ${ }^{+}$CTL tumour infiltration is a promising biomarker to predict the efficacy of ICIs but still has to be assessed.

Furthermore, genetic biomarkers have been studied. Mutation load has been described as a potential biomarker for response to ICIs because genomic alterations can encode neoantigens and change the anti-cancer immune response. A study of large databases of mutation load in solid tumours indeed showed that cancers with the highest mutation load had the highest response to anti-PD-1 and anti-PD-L1 treatments [96]. In addition, specific molecular profiles such as smoking-related signature, high neoantigen burden or DNA repair pathway mutations were found to be related to better responses to anti-PD-1 treatments [97]. In subgroup analyses of the clinical trials, nivolumab had a better efficacy in patients with KRAS-mutant NSCLC and was less efficient in patients with EGFR-mutant NSCLC in comparison with docetaxel in subgroup analyses [83, 84].

\section{Conclusions and perspectives}

In conclusion, various approaches to personalised medicine exist: 1) identification and targeting of a key driver oncogene that will predict for efficacy (e.g. EGFR mutations); 2) identification of a biomarker associated with higher efficacy of a specific treatment (e.g. PD-L1 immunohistochemistry); 3) identification of a biomarker associated with less toxicity (e.g. nonsquamous histology and bevacizumab). Treatment allocation according to histology is now the first level of personalised medicine in NSCLC management. Currently, all patients with advanced adenocarcinoma and nonsmokers with other histologies should be tested for EGFR mutations, ALK rearrangements and ROS1 fusion. BRAF mutations should be searched for too. When harbouring an EGFR sensitising mutation, $A L K$ or ROS1 rearrangements or BRAF mutations, patients with advanced NSCLC will receive bioguided therapy as first-line treatment, namely EGFR TKIs (i.e. gefinitib, erlotinib or afatinib) or ALK/ROS1 TKI (crizotinib) or BRAF inhibitors (dabrafenib and trametinib), respectively (table 3) [71]. RET fusion, MET exon14 mutation and HER2 mutations, but with a lower degree of evidence, have available targeted treatments as well, and should thus be tested for. These last markers can be tested sequentially if the tumour is negative for the three other markers, or simultaneously, through multiplex testing. In the research setting, ongoing molecularly 
stratified umbrella clinical trials offer the possibility to perform panel next-generation sequencing (NGS) analyses and to propose bioguided treatment in the context of clinical trials. One example is the SAFIR 02 Lung, a phase II randomised trial utilising high-throughput genomic testing and comparing bioguided treatment versus chemotherapy in maintenance in metastatic NSCLC. In the future, the single gene-single treatment approach that we are currently practising may be replaced by approaches considering a broader spectrum of molecular abnormalities as NGS analyses of tumours are generalised.

Recently, ICIs have revolutionised the treatment of advanced NSCLC. They became standard treatment in a second-line setting for NSCLC and their use may be extended in the near future with the results of ongoing studies in the first-line setting or in combination with chemotherapy, other ICIs or targeted therapies. Consequently, PD-L1 expression testing is now recommended before first-line treatment in patients with metastatic NSCLC with negative or unknown test results for EGFR mutations and ALK and ROS1 rearrangements. No biomarker is recommended for the use of nivolumab in NSCLC patients, while a minimum level of $1 \%$ and $50 \%$ PD-L1 tumour proportional score is required for the second- and first-line use of pembrolizumab in NSCLC patients, respectively. Additional biomarkers such as CD8 ${ }^{+}$CTL tumour infiltration, mutation load or molecular profile are being studied. However, their predictive effect has yet to be confirmed in clinical trials and future biomarkers have to be identified to refine the prediction of ICI efficacy.

Besides these successes and promises, personalised medicine has challenges and limits. When performing personalised medicine, a very important challenge is the need to standardise tests, both for laboratory procedures and their assessment for positivity. Illustrations of biomarker testing issues have been reported previously, with the failure to validate the use of ERCC1 expression to predict sensitivity to cisplatin. Reported initially as a favourable predictive factor for response to the platinum doublet in a first cohort of patients [98], the results could not be reproduced either in the same cohort or in an independent cohort [99]. The reasons for these failures were 1) differences in antibody batches and 2) the lack of specificity of the antibody for the relevant isoform of ERCC1. A more recent illustration of the test standardisation issue arose from the various tests used for PD-L1 expression in different trials testing the drugs against PD-1 and PD-L1 and the ongoing effort to homogenise a validated test to be used across laboratories to assess PD-L1 expression. Similarly, with other techniques, including molecular biology, rigorous assays and thresholds for clinically significant positivity need to be defined, as for EGFR mutation detection in ctDNA, for example. This example highlights the necessity of applying several methodological quality assurance steps before translating biomarkers use into clinical use. It is mandatory to standardise techniques and validate them across cohorts and laboratories. To ensure the biological and clinical relevance of biomarkers, it is also crucial to understanding the biology when designing biomarker assays and to define cut-offs for positivity that have clinical impact.

Another limit of personalised medicine lies in the development of specific resistance mechanisms to treatments. The resistance mutations developed after treatment with the different ALK inhibitors illustrate a new paradigm that will be observed with all TKIs: using a specific TKI is always followed by the emergence of resistant clones, and using sequential TKIs leads to an increasingly heterogeneous disease, which is much less amenable to precision medicine. The sequential use of drugs and/or their combinations will have to be carefully managed to keep the tumour sensitive to treatment for longer periods.

Finally, the next challenge for precision may be the need to integrate both biomarkers from the tumour and from the hosts, i.e. microbiota. Recent data have revealed that the gut microbiota influences the host response to anti-cancer drugs. Immunomodulations due to microbiota can confer variations in responses to immunotherapy, chemotherapy, radiotherapy and also targeted therapies. This field is currently widely under investigation and it is thus very likely that future precision medicine will combine pharmacogenomics information with custom microbial organisms or their specific metabolites to improve therapeutic responses and/or manage toxicities [100].

\section{References}

$1 \quad$ Siegel RL, Miller KD, Jemal A. Cancer statistics, 2016. CA Cancer J Clin 2016; 66: 7-30.

2 Goldstraw P, Chansky K, Crowley J, et al. The IASLC Lung Cancer Staging Project: proposals for revision of the TNM stage groupings in the forthcoming (eighth) edition of the TNM Classification for Lung Cancer. J Thorac Oncol 2016; 11: 39-51.

3 Tanaka F, Yoneda K. Adjuvant therapy following surgery in non-small cell lung cancer (NSCLC). Surg Today 2016; 46: 25-37.

4 Ettinger DS, Wood DE, Akerley W, et al. NCCN guidelines insights: non-small cell lung cancer, version 4.2016. J Natl Compr Canc Netw 2016; 14: 255-264.

5 Pfister DG, Johnson DH, Azzoli CG, et al. American Society of Clinical Oncology treatment of unresectable non-small-cell lung cancer guideline: update 2003. J Clin Oncol 2004; 22: 330-353.

6 Schiller JH, Harrington D, Belani CP, et al. Comparison of four chemotherapy regimens for advanced non-small-cell lung cancer. $N$ Engl J Med 2002; 346: 92-98. 

doublets in advanced non-small-cell lung cancer. J Clin Oncol 2002; 20: 4285-4291. plus cisplatin in the treatment of patients with advanced non-small-cell lung cancer: a Southwest Oncology Group trial. J Clin Oncol 2001; 19: 3210-3218.

9 Fossella F, Pereira JR, von Pawel J, et al. Randomized, multinational, phase III study of docetaxel plus platinum combinations versus vinorelbine plus cisplatin for advanced non-small-cell lung cancer: the TAX 326 study group. J Clin Oncol 2003; 21: 3016-3024.

10 Scagliotti GV, Parikh P, von Pawel J, et al. Phase III study comparing cisplatin plus gemcitabine with cisplatin plus pemetrexed in chemotherapy-naive patients with advanced-stage non-small-cell lung cancer. J Clin Oncol 2008; 26: 3543-3551.

11 Treat J, Scagliotti GV, Peng G, et al. Comparison of pemetrexed plus cisplatin with other first-line doublets in advanced non-small cell lung cancer (NSCLC): a combined analysis of three phase 3 trials. Lung Cancer 2012; 76: $222-227$.

12 Hanna N, Shepherd FA, Fossella FV, et al. Randomized phase III trial of pemetrexed versus docetaxel in patients with non-small-cell lung cancer previously treated with chemotherapy. J Clin Oncol 2004; 22: 1589-1597.

13 Scagliotti G, Hanna N, Fossella F, et al. The differential efficacy of pemetrexed according to NSCLC histology: a review of two phase III studies. Oncologist 2009; 14: 253-263.

14 Ciuleanu T, Brodowicz T, Zielinski C, et al. Maintenance pemetrexed plus best supportive care versus placebo plus best supportive care for non-small-cell lung cancer: a randomised, double-blind, phase 3 study. Lancet 2009; 374: 1432-1440.

15 Paz-Ares L, de Marinis F, Dediu M, et al. Maintenance therapy with pemetrexed plus best supportive care versus placebo plus best supportive care after induction therapy with pemetrexed plus cisplatin for advanced non-squamous non-small-cell lung cancer (PARAMOUNT): a double-blind, phase 3, randomised controlled trial. Lancet Oncol 2012; 13: 247-255.

16 Johnson DH, Fehrenbacher L, Novotny WF, et al. Randomized phase II trial comparing bevacizumab plus carboplatin and paclitaxel with carboplatin and paclitaxel alone in previously untreated locally advanced or metastatic non-small-cell lung cancer. J Clin Oncol 2004; 22: 2184-2191.

17 Sandler A, Gray R, Perry MC, et al. Paclitaxel-carboplatin alone or with bevacizumab for non-small-cell lung cancer. N Engl J Med 2006; 355: 2542-2550.

18 Reck M, von Pawel J, Zatloukal P, et al. Phase III trial of cisplatin plus gemcitabine with either placebo or bevacizumab as first-line therapy for nonsquamous non-small-cell lung cancer: AVAiL. J Clin Oncol 2009; 27: 1227-1234.

19 Reck M, von Pawel J, Zatloukal P, et al. Overall survival with cisplatin-gemcitabine and bevacizumab or placebo as first-line therapy for nonsquamous non-small-cell lung cancer: results from a randomised phase III trial (AVAiL). Ann Oncol 2010; 21: 1804-1809.

20 Paz-Ares L, Mezger J, Ciuleanu TE, et al. Necitumumab plus pemetrexed and cisplatin as first-line therapy in patients with stage IV non-squamous non-small-cell lung cancer (INSPIRE): an open-label, randomised, controlled phase 3 study. Lancet Oncol 2015; 16: 328-337.

21 Thatcher N, Hirsch FR, Luft AV, et al. Necitumumab plus gemcitabine and cisplatin versus gemcitabine and cisplatin alone as first-line therapy in patients with stage IV squamous non-small-cell lung cancer (SQUIRE): an open-label, randomised, controlled phase 3 trial. Lancet Oncol 2015; 16: 763-774.

22 Reck M, Kaiser R, Mellemgaard A, et al. Docetaxel plus nintedanib versus docetaxel plus placebo in patients with previously treated non-small-cell lung cancer (LUME-Lung 1): a phase 3, double-blind, randomised controlled trial. Lancet Oncol 2014; 15: 143-155.

23 Shepherd FA, Rodrigues Pereira J, Ciuleanu T, et al. Erlotinib in previously treated non-small-cell lung cancer. N Engl J Med 2005; 353: 123-132.

24 Thatcher N, Chang A, Parikh P, et al. Gefitinib plus best supportive care in previously treated patients with refractory advanced non-small-cell lung cancer: results from a randomised, placebo-controlled, multicentre study (Iressa Survival Evaluation in Lung Cancer). Lancet 2005; 366: 1527-1537.

25 Giaccone G, Herbst RS, Manegold C, et al. Gefitinib in combination with gemcitabine and cisplatin in advanced non-small-cell lung cancer: a phase III trial - INTACT 1. J Clin Oncol 2004; 22: 777-784.

26 Herbst RS, Giaccone G, Schiller JH, et al. Gefitinib in combination with paclitaxel and carboplatin in advanced non-small-cell lung cancer: a phase III trial - INTACT 2. J Clin Oncol 2004; 22: 785-794.

27 Paez JG, Jänne PA, Lee JC, et al. EGFR mutations in lung cancer: correlation with clinical response to gefitinib therapy. Science 2004; 304: 1497-1500.

28 Mok TS, Wu YL, Thongprasert S, et al. Gefitinib or carboplatin-paclitaxel in pulmonary adenocarcinoma. N Engl J Med 2009; 361: 947-957.

29 Mitsudomi T, Morita S, Yatabe Y, et al. Gefitinib versus cisplatin plus docetaxel in patients with non-small-cell lung cancer harbouring mutations of the epidermal growth factor receptor (WJTOG3405): an open label, randomised phase 3 trial. Lancet Oncol 2010; 11: 121-128.

30 Maemondo M, Inoue A, Kobayashi K, et al. Gefitinib or chemotherapy for non-small-cell lung cancer with mutated EGFR. N Engl J Med 2010; 362: 2380-2388.

31 Zhou C, Wu YL, Chen G, et al. Erlotinib versus chemotherapy as first-line treatment for patients with advanced EGFR mutation-positive non-small-cell lung cancer (OPTIMAL, CTONG-0802): a multicentre, open-label, randomised, phase 3 study. Lancet Oncol 2011; 12: 735-742.

32 Rosell R, Carcereny E, Gervais R, et al. Erlotinib versus standard chemotherapy as first-line treatment for European patients with advanced EGFR mutation-positive non-small-cell lung cancer (EURTAC): a multicentre, open-label, randomised phase 3 trial. Lancet Oncol 2012; 13: 239-246.

33 Wu YL, Zhou C, Liam CK, et al. First-line erlotinib versus gemcitabine/cisplatin in patients with advanced EGFR mutation-positive non-small-cell lung cancer: analyses from the phase III, randomized, open-label, ENSURE study. Ann Oncol 2015; 26: 1883-1889.

34 Sequist LV, Yang JC, Yamamoto N, et al. Phase III study of afatinib or cisplatin plus pemetrexed in patients with metastatic lung adenocarcinoma with EGFR mutations. J Clin Oncol 2013; 31: 3327-3334. 
Wu YL, Zhou C, Hu CP, et al. Afatinib versus cisplatin plus gemcitabine for first-line treatment of Asian patients with advanced non-small-cell lung cancer harbouring EGFR mutations (LUX-Lung 6): an open-label, randomised phase 3 trial. Lancet Oncol 2014; 15: 213-222.

36 Pao W, Miller VA, Politi KA, et al. Acquired resistance of lung adenocarcinomas to gefitinib or erlotinib is associated with a second mutation in the EGFR kinase domain. PLoS Med 2005; 2: e73.

37 Jänne PA, Yang JC-H, Kim D-W, et al. AZD9291 in EGFR inhibitor-resistant non-small-cell lung cancer. $N$ Engl J Med 2015; 372: 1689-1699.

38 Soda M, Choi YL, Enomoto M, et al. Identification of the transforming EML4-ALK fusion gene in non-small-cell lung cancer. Nature 2007; 448: 561-566.

39 Shaw AT, Kim DW, Nakagawa K, et al. Crizotinib versus chemotherapy in advanced ALK-positive lung cancer. N Engl J Med 2013; 368: 2385-2394.

40 Solomon BJ, Mok T, Kim DW, et al. First-line crizotinib versus chemotherapy in ALK-positive lung cancer. N Engl J Med 2014; 371: 2167-2177.

41 Lin JJ, Riely GJ, Shaw AT. Targeting ALK: precision medicine takes on drug resistance. Cancer Discov 2017; 7: 137-155.

42 Shaw AT, Kim DW, Mehra R, et al. Ceritinib in ALK-rearranged non-small-cell lung cancer. $N$ Engl J Med 2014; 370: 1189-1197.

43 Shaw AT, Gandhi L, Gadgeel S, et al. Alectinib in ALK-positive, crizotinib-resistant, non-small-cell lung cancer: a single-group, multicentre, phase 2 trial. Lancet Oncol 2016; 17: 234-242.

44 Katayama R. Therapeutic strategies and mechanisms of drug resistance in anaplastic lymphoma kinase (ALK)-rearranged lung cancer. Pharmacol Ther 2017; 177: 1-8.

45 Gettinger SN, Bazhenova LA, Langer CJ, et al. Activity and safety of brigatinib in ALK-rearranged non-small-cell lung cancer and other malignancies: a single-arm, open-label, phase 1/2 trial. Lancet Oncol 2016; 17: 1683-1696.

46 Novello S, Barlesi F, Califano R, et al. Metastatic non-small-cell lung cancer: ESMO clinical practice guidelines for diagnosis, treatment and follow-up. Ann Oncol 2016; 27: Suppl. 5, v1-v27.

47 Soria JC, Tan DSW, Chiari R, et al. First-line ceritinib versus platinum-based chemotherapy in advanced ALK-rearranged non-small-cell lung cancer (ASCEND-4): a randomised, open-label, phase 3 study. Lancet 2017; 389: 917-929.

48 Hida T, Nokihara H, Kondo $\mathrm{M}$, et al. Alectinib versus crizotinib in patients with ALK-positive non-small-cell lung cancer (J-ALEX): an open-label, randomised phase 3 trial. Lancet 2017; 390: 29-39.

49 Peters S, Camidge DR, Shaw AT, et al. Alectinib versus crizotinib in untreated ALK-positive non-small-cell lung cancer. N Engl J Med 2017; 377: 829-838.

50 Mazières J, Zalcman G, Crinò L, et al. Crizotinib therapy for advanced lung adenocarcinoma and a ROS1 rearrangement: results from the EUROS1 cohort. J Clin Oncol 2015; 33: 992-999.

51 Shaw AT, Ou SH, Bang YJ, et al. Crizotinib in ROS1-rearranged non-small-cell lung cancer. $N$ Engl J Med 2014; 371: $1963-1971$.

52 Lim SM, Kim HR, Lee JS, et al. Open-label, multicenter, phase II study of ceritinib in patients with non-small-cell lung cancer harboring ROS1 rearrangement. J Clin Oncol 2017; 35: 2613-2618.

53 Sarfaty M, Moore A, Neiman V, et al. RET fusion lung carcinoma: response to therapy and clinical features in a case series of 14 patients. Clin Lung Cancer 2017; 18: e223-e232.

54 Yoh K, Seto T, Satouchi M, et al. Vandetanib in patients with previously treated RET-rearranged advanced non-small-cell lung cancer (LURET): an open-label, multicentre phase 2 trial. Lancet Respir Med 2017; 5: 42-50.

55 Gautschi O, Milia J, Filleron T, et al. Targeting RET in patients with RET-rearranged lung cancers: results from the global, multicenter RET registry. J Clin Oncol 2017; 35: 1403-1410.

56 Lin JJ, Kennedy E, Sequist LV, et al. Clinical activity of alectinib in advanced RET-rearranged non-small cell lung cancer. J Thorac Oncol 2016; 11: 2027-2032.

57 Suryavanshi M, Shah A, Kumar D, et al. MET amplification and response to MET inhibitors in stage IV lung adenocarcinoma. Oncol Res Treat 2017; 40: 198-202.

58 Caparica R, Yen CT, Coudry R, et al. Responses to crizotinib can occur in high-level MET-amplified non-small cell lung cancer independent of MET exon 14 alterations. J Thorac Oncol 2017; 12: 141-144.

59 Jorge SE, Schulman S, Freed JA, et al. Responses to the multitargeted MET/ALK/ROS1 inhibitor crizotinib and co-occurring mutations in lung adenocarcinomas with MET amplification or MET exon 14 skipping mutation. Lung Cancer 2015; 90: 369-374.

60 Planchard D, Besse B, Groen HJM, et al. Dabrafenib plus trametinib in patients with previously treated BRAF (V600E)-mutant metastatic non-small cell lung cancer: an open-label, multicentre phase 2 trial. Lancet Oncol 2016; 17: 984-993.

61 Planchard D, Kim TM, Mazieres J, et al. Dabrafenib in patients with BRAF(V600E)-positive advanced non-small-cell lung cancer: a single-arm, multicentre, open-label, phase 2 trial. Lancet Oncol 2016; 17: 642-650.

62 Gautschi O, Milia J, Cabarrou B, et al. Targeted therapy for patients with BRAF-mutant lung cancer: results from the European EURAF cohort. J Thorac Oncol 2015; 10: 1451-1457.

63 Hyman DM, Puzanov I, Subbiah V, et al. Vemurafenib in multiple nonmelanoma cancers with BRAF V600 mutations. N Engl J Med 2015; 373: 726-736.

64 Cappuzzo F, Bemis L, Varella-Garcia M. HER2 mutation and response to trastuzumab therapy in non-small-cell lung cancer. N Engl J Med 2006; 354: 2619-2621.

65 Mazières J, Peters S, Lepage B, et al. Lung cancer that harbors an HER2 mutation: epidemiologic characteristics and therapeutic perspectives. J Clin Oncol 2013; 31: 1997-2003.

66 Barlesi F, Mazieres J, Merlio JP, et al. Routine molecular profiling of patients with advanced non-small-cell lung cancer: results of a 1-year nationwide programme of the French Cooperative Thoracic Intergroup (IFCT). Lancet 2016; 387: 1415-1426.

67 Mascaux C, Iannino N, Martin B, et al. The role of RAS oncogene in survival of patients with lung cancer: a systematic review of the literature with meta-analysis. Br J Cancer 2005; 92: 131-139.

68 Tomasini P, Serdjebi C, Khobta N, et al. EGFR and KRAS mutations predict the incidence and outcome of brain metastases in non-small cell lung cancer. Int J Mol Sci 2016; 17: E2132. 

21: $1450-1460$.

70 Zeng M, Lu J, Li L, et al. Potent and selective covalent quinazoline inhibitors of KRAS G12C. Cell Chem Biol 2017; 24: 1005-1016.e3.

71 Lindeman NI, Cagle PT, Beasley MB, et al. Molecular testing guideline for selection of lung cancer patients for EGFR and ALK tyrosine kinase inhibitors: guideline from the College of American Pathologists, International Association for the Study of Lung Cancer, and Association for Molecular Pathology. J Mol Diagn 2013; 15: $415-453$.

72 Masters GA, Temin S, Azzoli CG, et al. Systemic therapy for stage IV non-small-cell lung cancer: American Society of Clinical Oncology clinical practice guideline update. J Clin Oncol 2015; 33: 3488-3515.

73 Ettinger DS, Wood DE, Akerley W, et al. Non-small cell lung cancer, version 6.2015. J Natl Compr Canc Netw 2015; 13: 515-524.

74 Ulivi P. Non-invasive methods to monitor mechanisms of resistance to tyrosine kinase inhibitors in non-small-cell lung cancer: where do we stand? Int J Mol Sci 2016; 17: E1186.

75 Remon J, Caramella C, Jovelet C, et al. Osimertinib benefit in EGFR-mutant NSCLC patients with T790M-mutation detected by circulating tumour DNA. Ann Oncol 2017; 28: 784-790.

76 Aldarouish M, Wang C. Trends and advances in tumor immunology and lung cancer immunotherapy. $J$ Exp Clin Cancer Res 2016; 35: 157.

Ribas A. Tumor immunotherapy directed at PD-1. N Engl J Med 2012; 366: 2517-2519.

Hanahan D, Weinberg RA. Hallmarks of cancer: the next generation. Cell 2011; 144: 646-674.

79 Vansteenkiste JF, Cho BC, Vanakesa T, et al. Efficacy of the MAGE-A3 cancer immunotherapeutic as adjuvant therapy in patients with resected MAGE-A3-positive non-small-cell lung cancer (MAGRIT): a randomised, double-blind, placebo-controlled, phase 3 trial. Lancet Oncol 2016; 17: 822-835.

80 Butts C, Socinski MA, Mitchell PL, et al. Tecemotide (L-BLP25) versus placebo after chemoradiotherapy for stage III non-small-cell lung cancer (START): a randomised, double-blind, phase 3 trial. Lancet Oncol 2014; 15: 59-68.

81 Giaccone G, Bazhenova LA, Nemunaitis J, et al. A phase III study of belagenpumatucel-L, an allogeneic tumour cell vaccine, as maintenance therapy for non-small cell lung cancer. Eur J Cancer 2015; 51: 2321-2329.

82 Lynch TJ, Bondarenko I, Luft A, et al. Ipilimumab in combination with paclitaxel and carboplatin as first-line treatment in stage IIIB/IV non-small-cell lung cancer: results from a randomized, double-blind, multicenter phase II study. J Clin Oncol 2012; 30: 2046-2054.

83 Brahmer J, Reckamp KL, Baas P, et al. Nivolumab versus docetaxel in advanced squamous-cell non-small-cell lung cancer. N Engl J Med 2015; 373: 123-135.

84 Borghaei H, Paz-Ares L, Horn L, et al. Nivolumab versus docetaxel in advanced nonsquamous non-small-cell lung cancer. N Engl J Med 2015; 373: 1627-1639.

85 Herbst RS, Baas P, Kim DW, et al. Pembrolizumab versus docetaxel for previously treated, PD-L1-positive, advanced non-small-cell lung cancer (KEYNOTE-010): a randomised controlled trial. Lancet 2016; 387: $1540-1550$.

86 Reck M, Rodríguez-Abreu D, Robinson AG, et al. Pembrolizumab versus chemotherapy for PD-L1-positive non-small-cell lung cancer. N Engl J Med 2016; 375: 1823-1833.

87 Socinski M, Creelan B, Horn L, et al. NSCLC, metastatic CheckMate026: a phase 3 trial of nivolumab vs investigator's choice of platinum-based doublet chemotherapy as first-line therapy for stage IV/recurrent programmed death ligand 1 (PD-L1)-positive NSCLC. Ann Oncol 2016; 27: Suppl. 6, LBA7_PR.

88 Rittmeyer A, Barlesi F, Waterkamp D, et al. Atezolizumab versus docetaxel in patients with previously treated non-small-cell lung cancer (OAK): a phase 3, open-label, multicentre randomised controlled trial. Lancet 2017; 389: 255-265

89 Nishino M, Ramaiya NH, Awad MM, et al. PD-1 inhibitor-related pneumonitis in advanced cancer patients: radiographic patterns and clinical course. Clin Cancer Res 2016; 22: 6051-6060.

90 Chae YK, Pan A, Davis AA, et al. Biomarkers for PD-1/PD-L1 blockade therapy in non-small-cell lung cancer: is PD-L1 expression a good marker for patient selection? Clin Lung Cancer 2016; 17: 350-361.

91 Topalian SL, Taube JM, Anders RA, et al. Mechanism-driven biomarkers to guide immune checkpoint blockade in cancer therapy. Nat Rev Cancer 2016; 16: 275-287.

92 Hirsch FR, McElhinny A, Stanforth D, et al. PD-L1 immunohistochemistry assays for lung cancer: results from phase 1 of the Blueprint PD-L1 IHC Assay Comparison Project. J Thorac Oncol 2017; 12: 208-222.

93 Scheel AH, Dietel M, Heukamp LC, et al. Prädiktive PD-L1-Immunhistochemie beim nichtkleinzelligen Bronchialkarzinom: Aktueller Stand und Erfahrungen der ersten deutschen Harmonisierungsstudie [Predictive PD-L1 immunohistochemistry for non-small cell lung cancer: current state of the art and experiences of the first German harmonization study]. Pathologe 2016; 37: 557-567.

94 Taube JM, Klein A, Brahmer JR, et al. Association of PD-1, PD-1 ligands, and other features of the tumor immune microenvironment with response to anti-PD-1 therapy. Clin Cancer Res 2014; 20: 5064-5074.

95 Tumeh PC, Harview CL, Yearley JH, et al. PD-1 blockade induces responses by inhibiting adaptive immune resistance. Nature 2014; 515: 568-571.

96 Lawrence MS, Stojanov P, Polak P, et al. Mutational heterogeneity in cancer and the search for new cancer-associated genes. Nature 2013; 499: 214-218.

97 Rizvi NA, Hellmann MD, Snyder A, et al. Cancer immunology. Mutational landscape determines sensitivity to PD-1 blockade in non-small cell lung cancer. Science 2015; 348: 124-128.

98 Olaussen KA, Dunant A, Fouret P, et al. DNA repair by ERCC1 in non-small-cell lung cancer and cisplatin-based adjuvant chemotherapy. N Engl J Med 2006; 355: 983-991.

99 Friboulet L, Olaussen KA, Pignon JP, et al. ERCC1 isoform expression and DNA repair in non-small-cell lung cancer. N Engl J Med 2013; 368: 1101-1110.

100 Roy S, Trinchieri G. Microbiota: a key orchestrator of cancer therapy. Nat Rev Cancer 2017; 17: 271-285. 